\section{Kidney \\ Blood Pressure Research}

Review

\title{
Rheological Influence Upon the Glomerular Podocyte and Resultant Mechanotransduction
}

\author{
Simona Pichler Sekulic ${ }^{a}$ Miroslav Sekulic ${ }^{b}$ \\ a University of Belgrade School of Medicine, Belgrade, Serbia; ${ }^{b}$ Department of Laboratory \\ Medicine and Pathology, University of Minnesota, Minneapolis, MN, USA
}

\section{Key Words}

Fluid shear stress $\bullet$ Hyperfiltration $\cdot$ Kidney disease $\bullet$ Glomerulopathy $•$ Filtration fraction

\begin{abstract}
The glomerular podocyte is exposed to numerous mechanical forces as a constituent of the glomerular filtration apparatus. This includes fluid shear stress (FSS) displaced upon the podocytic foot process's apical, lateral, and basal surfaces. Even in the face of continuous flow the podocyte is capable of contributing to physiologic filtration, however with pathologic levels of hyperfiltration there is increased FSS placed upon the cell. The mechanisms by which the podocyte detects and responds to FSS are topics of recent investigations, with the aim to clarify the way these cells are injured and/or adapt in times of hyperfiltration and disease states. As the pathogenesis of numerous glomerulopathies is contingent on the status of the podocyte, understanding the manner that these cells can be modified by FSS is essential. Likewise, determination of the effect of such mechanical forces upon other resident cells of the renal corpuscle would reveal the contribution of FSS in the progression of glomerular diseases. The biochemical manner in which podocytes sense and respond to FSS, that is mechanotransduction, will be discussed.
\end{abstract}

Copyright $@ 2015$ S. Karger AG, Basel

\section{Introduction}

The glomerulus is the filtering unit of the nephron: where blood from the glomerular capillaries is filtered by way of the glomerular filtration apparatus producing a primary filtrate (also termed the ultrafiltrate). The primary filtrate is further modified down the length of the tubular nephron. Filtered material must pass through the selective components of the glomerular filtration apparatus in the following order: the fenestration endothelium, the 


\section{Kidney \\ Blood Pressure Research}

Kidney Blood Press Res 2015;40:176-187

\begin{tabular}{l|l}
\hline DOI: $10.1159 / 000368493$ & (C) 2015 S. Karger AG, Basel
\end{tabular}

Published online: March 30, 2015

www.karger.com/kbr

177

glomerular basement membrane (GBM), and the podocyte slit diaphragm [1]. The primary filtrate then enters Bowman's space - that is defined by the space between the podocytes (visceral epithelium) and the parietal epithelium - before continuing to the tubular nephron (Fig. 1). The podocyte is a highly differentiated cell that is comprised of a cell body and foot processes that adhere to the underlying GBM via their basal surface [2]. Foot processes are spaced with intervening areas spanned by a slit diaphragm that provides a size selective filter to passing material. It is well understood that the architecture of the podocyte and the maintenance of normal renal function are intimately intertwined [3-6].

As a component of the filtering unit of the nephron, the glomerular podocyte is exposed to a number of mechanical forces: fluid shear stress (FSS) and stretch [7, 8]. These forces can modulate within a physiologic range, however, there are instances when such forces are altered to become deleterious to the podocyte. Circumferential wall tension in the associated glomerular capillaries is countered by the buttressing podocytes, and produces an element of stretch upon the cell [9]. In states of increased flow through the glomerular capillaries with an elevated hydrostatic glomerular capillary pressure, there is transmission of the circumferential wall tension through the glomerular filtration apparatus to cause stretching of the podocyte. The intimate physical and paracrine relations held between the glomerular capillary endothelia, GBM, and podocyte are important as changes/insults to one structure are felt by the other elements of the filtration apparatus [10]. Stretch-related changes have been studied in podocytes and will not be the focus of this paper $[8,9,11]$. In the face of pathologic hemodynamics within the glomerulus, hyperfiltration and the concomitant increase of FSS can lead to glomerular injury. The glomerular filtration rate (GFR) rises secondary to increases in glomerular plasma flow as seen in the clinical setting of hypertension [12]. With hyperfiltration, the increased volume of primary filtrate passing over the surfaces of the podocyte incurs greater FSS (Fig. 1) [13]. A podocyte foot process is exposed on its apical, basal, and bilateral lateral surfaces (associated with the slit diaphragm) to FSS, and the FSS felt on the apical surface may be similar to that at the apical surface of parietal epithelial cells of Bowman's capsule (vide infra). It has been calculated that the FSS seen at the slit diaphragm is $8 \mathrm{~Pa}$ and $0.05 \mathrm{~Pa}$ on the apical surface of the podocyte, although these calculated estimates are relatively high when considering cultured podocytes are sensitive to FSS at values greater than $0.1 \mathrm{~Pa}[7,9]$.

FSS can be defined as the force per unit area acting parallel to a given surface: for now our surface of interest is the podocyte's cell membrane [9]. Laminar FSS $(\tau)$ is the product of the shear rate $(\gamma)$ and the viscosity $(\eta)$ of the fluid studied (in this case the primary filtrate). Turbulent, non-laminar, FSS develops if the velocity and/or the viscosity of the fluid are altered appropriately, and these parameters can be changed within the glomerulus [14]. It has been shown that cells react differently to laminar and turbulent FSS, and this may need further evaluation in future studies of podocytes [15]. In order to model FSS placed on the podocyte, Friedrich et al. defined it as such to aid in providing a calculated estimate:

$$
\tau=\frac{3 \eta \cdot f \cdot \text { SNGFR }}{\pi \cdot s^{2} \cdot\left(s+2 R_{T}\right)} \cdot \frac{z}{\sqrt{z \cdot(1-z)}}
$$

FSS at the glomerular tuft (podocyte surface) could now be estimated by providing the single-nephron glomerulus filtration rate (SNGFR), the fraction $(f)$ of the SNGFR continuing to the proximal tubule, radius of the glomerular tuft $\left(R_{\mathrm{T}}\right)$, the distance between the parietal epithelium and the glomerular tuft representing the width of Bowman's space $(s)$, and the coordinates that describe the axis from the vascular pole $(z=0)$ to the urinary pole $(z=$ 1) of the glomerular tuft [16]. This calculated estimate was applied in recent work that illustrated in uninephrectomized rodents with a reduction of nephron number that there would be increased FSS placed upon podocytes [17]. Further work could determine the true applicability of this calculated estimate of FSS on the podocyte in the complicated milieu that is Bowman's space. 


\section{Kidney Blood Pressure Research}

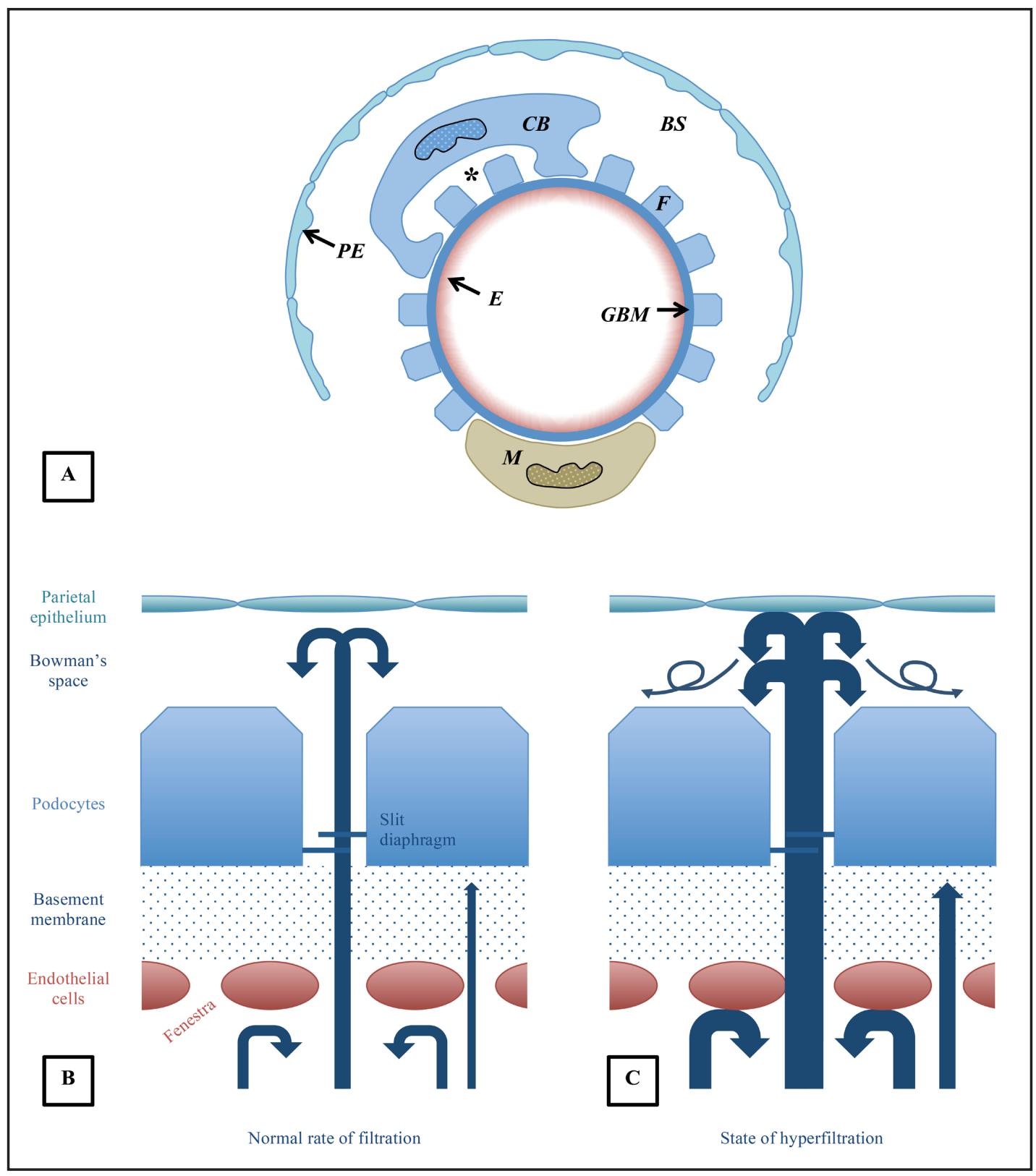

Fig. 1. The microanatomy of the glomerulus and its constituents. (A) A simplified view of the glomerular filtration apparatus with the capillary endothelia $(E)$, glomerular basement membrane $(G B M)$, and overlying podocytes. Also related to glomerular capillary loops are mesangial cells $(M)$. The podocyte is made up of a cell body $(C B)$ and foot processes $(F)$ that associate with the GBM. Between the podocyte and the opposing parietal epithelium $(P E)$ is Bowman's space $(B S)$. Filtrate can either enter Bowman's space directly after passage through the slit diaphragm, or it can enter via the subpodocyte space $\left(^{*}\right)$ through exit pores (not depicted). (B and C) A closer look at the glomerular filtration apparatus is depicted. Filtered material has to pass through (in such order) the fenestrated endothelial cells, GBM, and the slit diaphragm spanning the space between adjacent podocyte foot processes. This filtrate enters Bowman's space which is continuous with the tubular nephron. Under normal conditions and filtration, the podocyte is exposed to fluid flow on its basal surface (associated with the underlying GBM), its lateral surface (associated with the slit diaphragm), and its apical surface. In conditions that result in hyperfiltration (C), there is an increase of fluid flowing across the aforementioned podocyte surfaces, and there is also increased fluid shear stress placed upon the other resident cells found in the glomerulus. 


\section{Kidney Blood Pressure Research}

The podocyte has been determined to be a key component in the pathogenesis of numerous glomerulopathies, and better understanding of podocyte cell biology will aid in determining mechanisms of disease and avenues of therapeutic targeting. The mechanisms by which a podocyte recognizes a mechanical stimulus such as FSS and responds are the focus of this review. It should be iterated that the numerous mechanical forces placed on the podocyte most likely illicit responses at the cellular level that have some overlapping signaling pathways with confounding adaptations.

The podocyte's placement within the glomerular microanatomy and its importance with regards to FSS

Canonical appreciation of glomerular microanatomy with a podocentric perspective

The podocyte is uniquely situated as the final selective component of the glomerular filtration apparatus. The glomerular filtration apparatus is the filtering unit of the glomerulus, and is composed of the previously described fenestrated endothelia, GBM, and the podocyte with its associated slit diaphragm. Specifically the podocyte foot processes are affixed basally to the underlying basement membrane by way of integrins, tetraspanins, and dystroglycans $[18,19]$. Laterally, the foot processes are separated from each other by the slit diaphragm that spans the space between. The slit diaphragm is made up of numerous proteins - most notably nephrin - which are associated via intracellular interactions with both the structural and functional integrity of the podocyte [20]. The slit diaphragm is typically the only physical contact between adjacent foot process: a relationship that is lost in different glomerulopathies [21]. Rodewald and Karnovsky first illustrated the slit diaphragm to have an ultrastructural zipper-like configuration, and it has since been proven to act as a size selective filter to passing material [1]. The apical surface faces Bowman's space (or to be expanded upon further later: the subpodocyte space) and is notable for the anionic charge provided by membrane-associated proteins such as GLEPP-1, podocalyxin, and podoplanin [22-24]. This negative charge is thought to be in part responsible for maintaining separation between adjacent foot processes as well as the spacing between podocytes and parietal epithelium, thereby maintaining glomerular structure and function $[25,26]$. The three surfaces described are associated with the podocyte's actin cytoskeleton via protein-protein interactions, and as such, signaling/activation of elements from one aspect of the podocyte influences the podocyte's architecture in total. With that in mind, as most of the podocyte is exposed to FSS, mechanosensation could derive from any part of the cell.

The distance between adjacent foot processes - sometimes termed the filtration slit or the interpodocyte space - in human glomeruli has been measured at 30-40 nm [27]. Podocyte foot processes interact with the underlying associated GBM: with this $400 \mathrm{~nm}$ thick basement membrane comprised of type IV collagen, fibronectin, entactin, heparin sulfate proteoglycan, and laminin [28-31]. Together, the GBM and podocyte layers contribute the greatest resistance of flow of filtrate through the glomerular filtration apparatus. Furthermore, the slit diaphragm provides the greatest resistance of flow as the filtrate passes into the filtration slit, with minimal resistance by drag along the lateral surfaces of the foot processes [32].

\section{Novel glomerular microanatomy: the subpodocyte space}

Ultrastructural work conducted by Neal et al. has led to the appreciation of the subpodocyte space: a space defined by the GBM and the podocyte foot processes (with the slit diaphragm) opposed by the underside of other portions of the podocyte [33, 34]. The investigators recognized that primary filtrate could follow a pathway starting after the slit diaphragm that entered the subpodocyte space and continued through exit pores into the urinary collection space (termed peripheral urinary space) classically considered as Bowman's space. It has been shown that this novel pathway offers significant resistance of flow of primary filtrate, most notably in the subpodocyte space's exit pores [35]. 


\section{Kidney \\ Blood Pressure Research}

Kidney Blood Press Res 2015;40:176-187

\begin{tabular}{l|l}
\hline DOI: $10.1159 / 000368493$ & (c) 2015 S. Karger AG, Basel
\end{tabular}

Published online: March 30, 2015

www.karger.com $/ \mathrm{kbr}$

Approximately $60 \%$ of the glomerular filtration apparatus appears to be covered by routes of filtration involving the subpodocyte space, thus implicating its importance in regulating filtration. Additionally, the permeability characteristics of solute passage involving the subpodocyte spaces and areas "unbounded" by this space with direct passage of filtrate from the slit diaphragm into Bowman's space differ [36]. The subpodocyte space could offer a locale for which the unique fluid dynamics act as a stimulus of mechanosensors of FSS. Further investigations will be necessary to fully understand the role of the subpodocyte space in the regulation of glomerular filtration, its contribution to overall function of the glomerular filtration apparatus, and the intrinsic fluid dynamics and FSS affecting the bounding podocyte surfaces.

\section{Mechanisms by which hyperfiltration and FSS develop within the glomerulus}

The GFR is a measurement that is utilized clinically to reflect whole kidney function and to stratify patients for treatment and prognosis [37]. Factors that can alter GFR include renal perfusion rate, the filtration surface area, permeability of the filter, and hydrostatic and oncotic pressures. The relation between these factors and GFR can be expressed as follows:

$$
\begin{aligned}
& G F R=k \cdot S\left(P_{g c}-P_{b s}-\pi_{p}\right) \\
& K_{\mathrm{f}}=k \cdot S
\end{aligned}
$$

This includes the hydraulic permeability of the filter ( $k$; in some literature represented by $L p$ ), $S$ the surface area of the filter, $P_{g c}$ the hydraulic pressure within the glomerular capillary, $P_{b s}$ the hydraulic pressure within Bowman's space, and $\pi_{p}$ the oncotic pressure of the plasma within the glomerular capillary. The product of the filter's hydraulic permeability $(k)$ and the filtering surface area $(S)$ provides the ultrafiltration coefficient $\left(K_{\mathrm{f}}\right)$ [31]. This equation assumes that the primary filtrate is free of protein contributing to oncotic pressure within Bowman's space $\left(\pi_{b s}\right)$ : however this may not be the case in glomerulopathies with protein loss into the primary filtrate. In such instances, the reflection coefficient of proteins $(s)$ for the glomerular filter must be also accounted for. A more appropriate expression of the GFR in the pathologic state would be as such:

$$
G F R=K_{\mathrm{f}}\left[\left(P_{g c}-P_{b s}\right)-s\left(\pi_{p}-\pi_{b s}\right)\right]
$$

Modulation of the determinants of GFR will obviously result in changes in functional filtration. A state of hyperfiltration will develop in the setting of: hypertension (increasing $P_{g c}$ ), with increased permeability of the filter (increasing $k$ ) for the aberrant passage of plasma proteins ( $s$ is near 0 when absolutely permeable and near 1 when absolutely impermeable), or in the instance when there is leakage of protein into Bowman's space and the filter's structure is compromised (increasing $\pi_{b s}$ ). Modulation of the determinants of the GFR can lead to subsequent increases in filtration, and applying this increase of filtration at the level of a single glomerulus/nephron to Eq. 1 reveals a rise of FSS upon the podocyte.

Hyperfiltration can occur with expanded renal perfusion: often seen in the clinical setting of hypertension and also with a decrease of total nephron number (as in congenital anomalies of renal agenesis and reduced nephron number) $[37,38]$. In the earliest stages of diabetes mellitus hyperfiltration has been appreciated, portending poor clinical outcomes [39]. In obesity with increased body mass, there is a compensatory increase of cardiac output that results in increased blood pressure and hyperfiltration faced by the static (or decreasing) number of glomeruli $[40,41]$. Inflammatory cytokines, hormones, free fatty acids, smoking, and increased salt intake in the obese patient population are all associated 


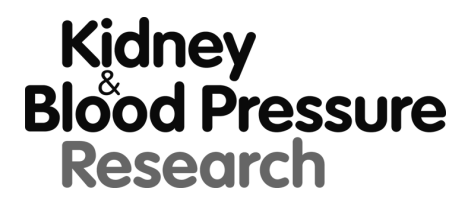

Kidney Blood Press Res 2015;40:176-187

\begin{tabular}{l|l}
\hline DOI: $10.1159 / 000368493$ & C 2015 S. Karger AG, Basel
\end{tabular}

Published online: March 30, 2015

www.karger.com $/ \mathrm{kbr}$

with hyperfiltration. Therefore the role of hyperfiltration and resultant FSS within the glomerulus is relevant in highly prevalent diseased states.

The described surfaces of the podocyte are perpetually exposed to fluid flow. Under physiologic conditions the GFR of a healthy individual is considered to be around 125 $\mathrm{mL} / \mathrm{min} / 1.73 \mathrm{~m}^{2}$, however there are varying definitions of what constitutes glomerular hyperfiltration. A GFR of two standard deviations above the mean for matched healthy individuals has been considered a definition of hyperfiltration [42]. Others have defined hyperfiltration as a measured value above thresholds ranging from 125 to $175 \mathrm{~mL} /$ $\mathrm{min} / 1.73 \mathrm{~m}^{2}$. It should be noted that these attempts of defining glomerular hyperfiltration are for clinical utility and are made at the level of the whole kidney and not that of a single glomerulus. This is important to recognize as total, whole kidney GFR could be reduced while concurrently a subset of glomeruli experience hyperfiltration. Glomerular hyperfiltration has also been thought of as an increase of the filtration fraction, and this may be more representative of the fluid flow the podocyte is exposed. The filtration fraction is defined as the ratio of GFR to renal plasma flow (RPF), and is normally 0.16-0.20 [43, 44]. This relationship is important to keep in mind as not every instance of increased GFR necessarily equates to podocyte damage, i.e. during pregnancy. Normal pregnancy is associated with increases of GFR and RPF, but at the same time there is maintenance of a normal filtration rate and absence of the development of glomerular capillary hypertension and podocyte injury $[10,45]$. On the other hand, increased GFR and filtration fraction can be injurious to the glomerulus and podocyte. In animal models of diabetic nephropathy it seems as though a relatively greater dilation of the afferent artery compared to that of the efferent artery results in an increased GFR, increased glomerular capillary hydraulic pressure, and an increase of the filtration fraction [46, 47]. The role played by angiotensin converting enzyme (ACE) inhibitors in alleviating increased glomerular capillary hydraulic pressure in such patients is evident through its ability to cause dilation of the efferent artery.

\section{Currently understood mechanisms of FSS-mediated mechanotransduction in podocytes}

The earliest examination of the role of FSS on the podocyte was provided by the work of Friedrich and colleagues [16]. They noted that the application of FSS (up to 0.25 dyne $/ \mathrm{cm}^{2}$ ) upon cultured podocytes would produce changes of the cellular architecture via reorganization of the actin cytoskeleton and detachment of some cells. The F-actin configuration changed with transverse fibers notably reduced, a cortical actin network was observed, and vinculin (typically co-localizes with F-actin) was found in a diffuse cytoplasmic distribution. Ruffles and lamellipodia that formed after the application of FSS (0.015-0.25 dyne $/ \mathrm{cm}^{2}$ ) contained cortactin (an actin nucleation protein) that was redistributed to the cell margins. Furthermore, by using broadband tyrosine kinase inhibitors they illustrated the role of tyrosine kinases in podocyte adaptation and maintenance of the actin cytoskeleton in the face of increased FSS. Similar cytologic changes were observed by others after the application of FSS ( 2 dynes $/ \mathrm{cm}^{2}$ ) on cultured podocytes characterized by decreased transversal F-actin stress filaments and the appearance of a cortical actin network [48]. It seems as though there is modulation of the actin cytoskeleton after exposure to FSS, and reconfiguration of the podocyte's cytologic architecture is observed post stimulation [7]. With the changes of the actin cytoskeleton, it is apparent that FSS elicits a structural mechanoresponse in the podocyte.

The mechanoresponse to FSS by the podocyte has been since shown to involve different intracellular signaling pathways. Huang et al. showed that in addition to inducing apoptosis in cultured podocytes, that FSS induced c-Src (a tyrosine kinase) phosphorylation, phospholipase ( $\left.\mathrm{PLD}_{1}\right)$ activity, production of phosphatidic acid, and activation of mammalian target of rapamycin (mTOR) [49]. The downstream actions of mTOR activation include 


\section{Kidney Blood Pressure Research}

mitochondrial metabolism, autophagy, protein/lipid synthesis, modulation of the actin cytoskeleton, and other cellular activities [50]. Within podocytes, mTOR has a role in cellular hypertrophy that may represent a mechanism of adaptation in light of podocyte loss in glomerulopathies.

Cultured podocytes exposed to FSS $\left(2\right.$ dynes $\left./ \mathrm{cm}^{2}\right)$ caused an increase of intracellular prostaglandin $\mathrm{E}_{2}\left(\mathrm{PGE}_{2}\right.$ ) protein and cyclooxygenase-2 (COX-2) mRNA, while COX-1 mRNA quantity was unchanged thus showing an element of specificity in the cellular response [48]. Srivastava et al. also showed that FSS caused an increase of E-prostanoid receptor 2 (EP2) protein and mRNA expression in cultured podocytes, and increased EP2 protein expression in glomeruli of Os/+ oligosyndactyl mice (a model of hyperfiltration) [51]. Further work with cultured podocytes exposed to FSS showed increased COX-2 and EP2 gene and protein expression, and increased intracellular and secreted $\mathrm{PGE}_{2}$ [52]. EP2 has been shown to mediate both G protein-coupled (modulating cAMP, Rap1/2, et al.) and G proteinindependent (modulating $\beta$-arrestin, Src/EGFR, ERK, F-actin, et al.) downstream signaling [53]. An experiment placing isolated glomeruli in a flow chamber showed that FSS increased the filter's permeability to albumin, and this effect was attenuated with the application of indomethacin. The data collected by Srivastava and colleagues illustrated that activation of the COX-2/PGE 2 /EP2 signaling pathway could alter podocyte function and provide targets for therapeutic intervention in the setting of hyperfiltration.

To date, there is no clear mechanism by which the podocyte senses the mechanical force of FSS. Mechanotransduction is comprised of the cell first being able to sense the force being transmitted/applied, followed by a response [54]. It seems that regardless of the cell/system studied, mechanical forces drive change in protein conformation that leads to downstream effects (i.e. opening of a mechanically gated ion channel or exposure of a protein domain for interaction with substrates). Unfortunately the sensor(s) of FSS in the podocyte has/have not yet been illustrated. A schematic depicting the podocyte specific, FSS-initiated signaling pathways known to date are depicted in Fig. 2.

\section{Postulated mechanisms of FSS-mediated mechanotransduction in podocytes}

As stated above, the podocyte sensor (or sensors) of FSS is not known, but there are possible components of the podocyte that could play such a part and are discussed as follows (Fig. 2). Junctional proteins have been shown to sense FSS in endothelial cells, including cadherin, which was previously observed to localize at the slit diaphragm $[55,56]$. It could be suggested that the slit diaphragm acts as a sensor of FSS, as the structure has already been implicated in podocyte signaling cascades [20]. Integrins have been thought to act as mechanosensors of FSS in endothelial cells, and were shown to mediate downstream activation of ERK1/2 or AKT [57]. While the study by Chretein did not show conformational change of integrins, others have shown that integrins do in fact undergo such structural change after the application of mechanical force [58]. Integrins are well established as being integral in the maintenance of the podocyte's actin cytoskeleton as well as modulating the architecture of the specialized foot processes by intracellular signaling [59].

The role of the transient receptor potential canonical (TRPC) family of non-selective, $\mathrm{Ca}^{2+}$ conducting channels in podocytopathies has been examined and mutations in TRPC6 have been implicated in the development of adult onset focal segmental glomerulosclerosis [60-62]. Additionally, TRPC5 and TRPC6 have been noted to regulate the actin cytoskeleton of podocytes via Rac1 and RhoA respectively $[62,63]$. Hypoosmotic stretch induced TRPC6 activity was noted in CHO-K1 cells transiently expressing the ion channel, therefore showing a response to a mechanical stimulus [64]. A mechanically sensitive potassium channel was found in cultured podocytes that drove calcium influx by way of stretch induced hyperpolarization - this potassium channel could represent a senor that leads to TRPCmediated actin modification [65]. 


\section{Kidney Blood Pressure Research}

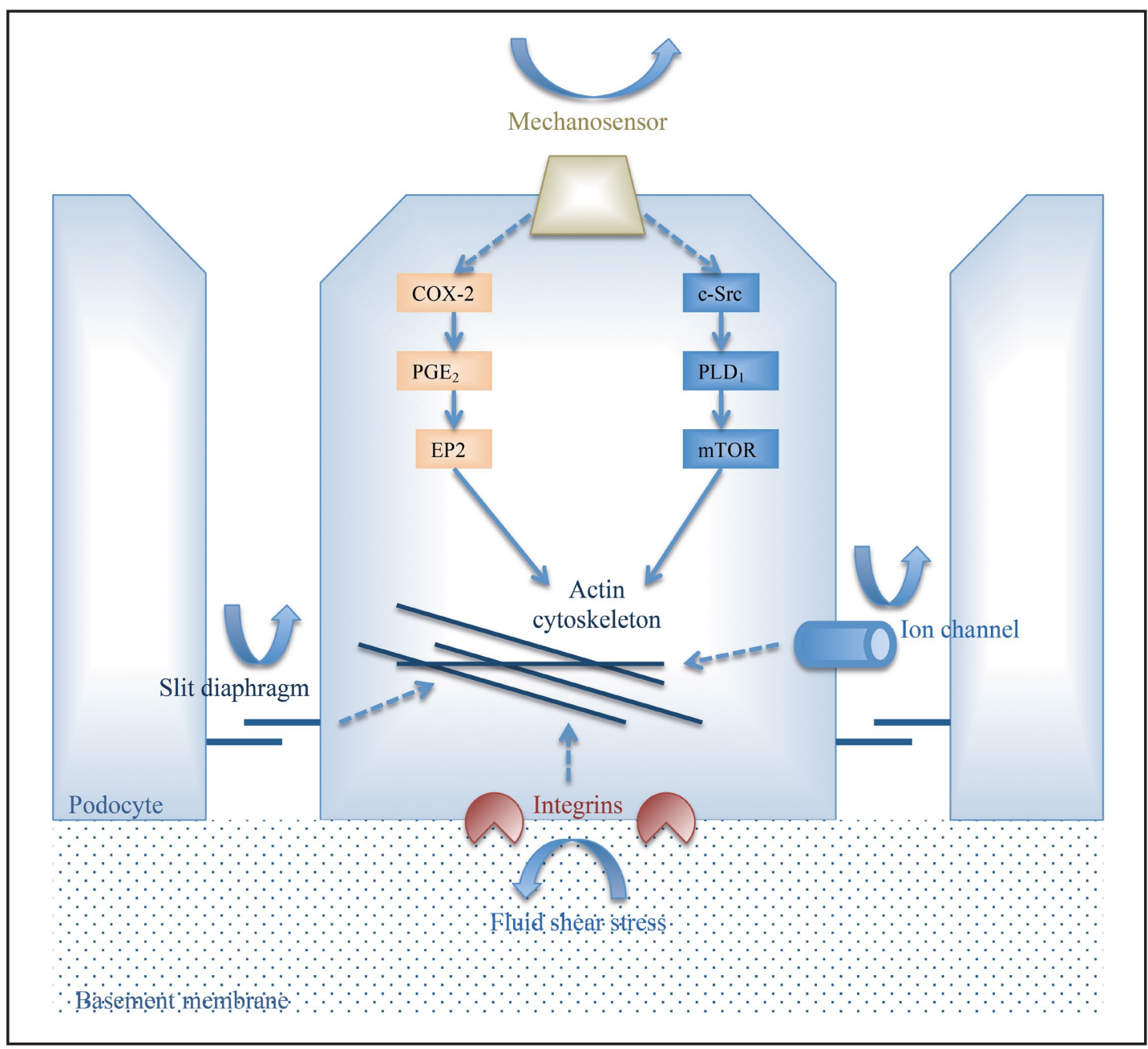

Fig. 2. The podocyte specific signaling cascades initiated by fluid shear stress (FSS) are shown along with postulated mechanosensors of FSS. The podocyte foot processes are associated via integrins to the underlying glomerular basement membrane and are in association with the adjacent foot processes via the slit diaphragm. The common response seen in podocytes to FSS is rearrangement of the actin cytoskeleton, and this is mediated through signaling pathways initiated in response to such mechanical stimulation. The $\mathrm{COX}-2 / \mathrm{PGE}_{2} / \mathrm{EP} 2$ and the $\mathrm{c}-\mathrm{Src} / \mathrm{PLD}_{1} / \mathrm{mTOR}$ signaling axes are activated within podocytes in response to FSS, though the specific mechanosensors for each have yet to be elucidated. We propose that podocyte specific mechanosensors of FSS could include the slit diaphragm, integrins, and cell membrane associated ion channels. The known signaling pathways are denoted with solid arrows while postulated pathways are denoted with dashed arrows.

As mentioned before, there may be overlap of signaling pathways activated in response to FSS and mechanical stretch. To touch on briefly, podocytes have been found to have increased intracellular calcium, increased ERK1/2 phosphorylation, and increased secreted protein acidic and rich in cysteine (SPARC) in response to stretch $[11,66]$. Podocyte osteopontin in concert with integrins have been shown to modulate the actin cytoskeleton in reaction to stretch, with concurrent participation of FAK, Src, MAPK, and PI 3-kinase [67]. While FSSinduced intracellular signaling was described earlier to activate $\mathrm{PGE}_{2}$, mechanical stretch was also shown to increase $\mathrm{PGE}_{2}$ activity in podocytes $[68,69]$. Whether similarly involved signaling molecules/pathways are activated after the application of FSS on a podocyte is yet to be comprehensively illustrated. 


\section{Kidney \\ Blood Pressure Research}

Pichler Sekulic/Sekulic: Rheological Influence Upon the Podocyte

\section{Conclusion}

The podocyte is a highly specialized, differentiated cell whose reaction to changes in surface FSS and increased fluid flow would be expected to be unique and specific to this cell type. While one could attempt to extrapolate the expected reaction of podocyte change to FSS from data gleaned from the study of other cells types (i.e. osteocytes and endothelial cells), the unique location and function of the podocyte requires focused investigation. Prior studies examining other cells types would be useful in at least providing starting points of investigation in attempting to see if similar manners of mechanotransduction exist. Further investigation of such mechanical force on the podocyte should shed light on a cell that is perpetually exposed to fluid flow. In particular, in vivo microscopic techniques could be used to evaluate changes of flow and the effect on podocytes and other elements of the glomerulus in real-time. It is imperative to understand podocyte response and injury secondary to increased FSS and altered intra-glomerular fluid dynamics.

A practical application of studying the reaction of podocytes to FSS is in the understanding of the therapeutic effects of ACE inhibitors. The role of ACE inhibitors in decreasing glomerular capillary hydraulic pressure $\left(P_{g c}\right)$ via vasodilatory effect on the efferent arteries is well established. Vasodilation and the reduction of resistance of flow through the efferent artery lend to a decrease in filtration fraction and the flow of filtrate exposed to the podocyte $[8,70]$. ACE inhibitors have been efficient in delaying the progression of chronic kidney disease and this action may partially be through the reduction of pathologic forces (injurious FSS and stretch) within the injured glomerulus. This discussion should also note the renoprotective benefits of ACE inhibitors are more than just hemodynamic in nature: they also modulate the direct detrimental effect of angiotensin II upon podocytes [71].

It should not be forgotten that the parietal epithelium of Bowman's capsule is likely exposed to similar FSS as some portions of the podocyte, and this implies that such force could injure and destabilize these cells. Obviously the structure and placement of parietal epithelium differs from that of the podocyte, so the expected FSS, the threshold for reaction to mechanostimulation, and the response by these cells would vary. The role of the parietal epithelium in glomerulopathies is not entirely clear, but it could be that altered hemodynamics within Bowman's space are to explain some of the changes seen in the parietal epithelium in pathologic lesions. While recent work has observed changes in parietal epithelium after the loss of podocytes, the mechanisms of parietal cell alterations are not well understood, and the part played by altered fluid dynamics within Bowman's space should be examined [72]. On the same note, the influence of FSS upon all resident cells of the glomerulus should be examined to elucidate the role of such mechanical force in the pathogenesis of glomerulopathies.

\section{Disclosure Statement}

The authors declare that they have no conflicts of interests.

\section{References}

1 Rodewald R, Karnovsky MJ: Porous substructure of the glomerular slit diaphragm in the rat and mouse. J Cell Biol 1974;60:423-433.

2 Pavenstädt H, Kriz W, Kretzler M: Cell biology of the glomerular podocyte. Physiol Rev 2003;83:253-307.

3 Jefferson JA, Alpers CE, Shankland SJ: Podocyte biology for the bedside. Am J Kidney Dis 2011;58:835-845.

4 Ly J, Alexander M, Quaggin SE: A podocentric view of nephrology. Curr Opin Nephrol Hypertens 2004;13:299-305. 


\section{Kidney \\ Blood Pressure Research}

Kidney Blood Press Res 2015;40:176-187

\begin{tabular}{l|l}
\hline DOI: $10.1159 / 000368493$ & C 2015 S. Karger AG, Basel
\end{tabular}

Published online: March 30, 2015

www.karger.com/kbr

$5 \quad$ Menzel S, Moeller MJ: Role of the podocyte in proteinuria. Pediatr Nephrol 2011;26:1775-1780.

6 Mundel P, Reiser J: Proteinuria: An enzymatic disease of the podocyte? Kidney Int 2010;77:571-580.

7 Endlich N, Endlich K: Stretch, tension and adhesion - adaptive mechanisms of the actin cytoskeleton in podocytes. Eur J Cell Biol 2006;85:229-234.

8 Kriz W, Lemley KV: A potential role for mechanical forces in the detachment of podocytes and the progression of ckd. J Am Soc Nephrol 2015;26:258-269.

9 Endlich N, Endlich K: The challenge and response of podocytes to glomerular hypertension. Semin Nephrol 2012;32:327-341.

10 Sekulic M, Pichler Sekulic S: A compendium of urinary biomarkers indicative of glomerular podocytopathy. Patholog Res Int 2013;2013:782395.

11 Eekhoff A, Bonakdar N, Alonso JL, Hoffmann B, Goldmann WH: Glomerular podocytes: A study of mechanical properties and mechano-chemical signaling. Biochem Biophys Res Commun 2011;406:229233.

12 Deen WM, Maddox DA, Robertson CR, Brenner BM: Dynamics of glomerular ultrafiltration in the rat. Vii. Response to reduced renal mass. Am J Physiol 1974;227:556-562.

13 Haraldsson B, Nyström J, Deen WM: Properties of the glomerular barrier and mechanisms of proteinuria. Physiol Rev 2008;88:451-487.

14 Elger M, Sakai T, Kriz W: The vascular pole of the renal glomerulus of rat. Adv Anat Embryol Cell Biol 1998;139:1-98.

15 Mohan S, Mohan N, Sprague EA: Differential activation of nf-kappa b in human aortic endothelial cells conditioned to specific flow environments. Am J Physiol 1997;273:C572-578.

16 Friedrich C, Endlich N, Kriz W, Endlich K: Podocytes are sensitive to fluid shear stress in vitro. Am J Physiol Renal Physiol 2006;291:F856-865.

17 Srivastava T, Celsi GE, Sharma M, Dai H, McCarthy ET, Ruiz M, Cudmore PA, Alon US, Sharma R, Savin VA: Fluid flow shear stress over podocytes is increased in the solitary kidney. Nephrol Dial Transplant 2014;29:65-72.

18 Sachs N, Kreft M, van den Bergh Weerman MA, Beynon AJ, Peters TA, Weening JJ, Sonnenberg A: Kidney failure in mice lacking the tetraspanin cd151. J Cell Biol 2006;175:33-39.

19 Vogtländer NP, Dijkman H, Bakker MA, Campbell KP, van der Vlag J, Berden JH: Localization of alphadystroglycan on the podocyte: From top to toe. J Histochem Cytochem 2005;53:1345-1353.

20 Huber TB, Kottgen M, Schilling B, Walz G, Benzing T: Interaction with podocin facilitates nephrin signaling. J Biol Chem 2001;276:41543-41546.

21 de Zoysa JR, Topham PS: Podocyte biology in human disease. Nephrology (Carlton) 2005;10:362-367.

22 Breiteneder-Geleff S, Matsui K, Soleiman A, Meraner P, Poczewski H, Kalt R, Schaffner G, Kerjaschki D: Podoplanin, novel 43-kd membrane protein of glomerular epithelial cells, is down-regulated in puromycin nephrosis. Am J Pathol 1997;151:1141-1152.

23 Schnabel E, Dekan G, Miettinen A, Farquhar MG: Biogenesis of podocalyxin--the major glomerular sialoglycoprotein--in the newborn rat kidney. Eur J Cell Biol 1989;48:313-326.

24 Wharram BL, Goyal M, Gillespie PJ, Wiggins JE, Kershaw DB, Holzman LB, Dysko RC, Saunders TL, Samuelson LC, Wiggins RC: Altered podocyte structure in glepp1 (ptpro)-deficient mice associated with hypertension and low glomerular filtration rate. J Clin Invest 2000;106:1281-1290.

25 Shankland SJ: The podocyte's response to injury: Role in proteinuria and glomerulosclerosis. Kidney Int 2006;69:2131-2147.

26 Kerjaschki D: Dysfunctions of cell biological mechanisms of visceral epithelial cell (podocytes) in glomerular diseases. Kidney Int 1994;45:300-313.

27 Wartiovaara J, Ofverstedt LG, Khoshnoodi J, Zhang J, Mäkelä E, Sandin S, Ruotsalainen V, Cheng RH, Jalanko H, Skoglund U, Tryggvason K: Nephrin strands contribute to a porous slit diaphragm scaffold as revealed by electron tomography. J Clin Invest 2004;114:1475-1483.

28 Lafayette RA, Druzin M, Sibley R, Derby G, Malik T, Huie P, Polhemus C, Deen WM, Myers BD: Nature of glomerular dysfunction in pre-eclampsia. Kidney Int 1998;54:1240-1249.

29 Squarer A, Lemley KV, Ambalavanan S, Kristal B, Deen WM, Sibley R, Anderson L, Myers BD: Mechanisms of progressive glomerular injury in membranous nephropathy. J Am Soc Nephrol 1998;9:1389-1398. 


\section{Kidney \\ Blood Pressure Research}

30 Laurie GW, Leblond CP, Inoue S, Martin GR, Chung A: Fine structure of the glomerular basement membrane and immunolocalization of five basement membrane components to the lamina densa (basal lamina) and its extensions in both glomeruli and tubules of the rat kidney. Am J Anat 1984;169:463-481.

31 Deen WM, Lazzara MJ, Myers BD: Structural determinants of glomerular permeability. Am J Physiol Renal Physiol 2001;281:F579-596.

32 Drumond MC, Deen WM: Stokes flow through a row of cylinders between parallel walls: Model for the glomerular slit diaphragm. J Biomech Eng 1994;116:184-189.

33 Neal CR, Crook H, Bell E, Harper SJ, Bates DO: Three-dimensional reconstruction of glomeruli by electron microscopy reveals a distinct restrictive urinary subpodocyte space. J Am Soc Nephrol 2005;16:1223-1235.

34 Arkill KP, Qvortrup K, Starborg T, Mantell JM, Knupp C, Michel CC, Harper SJ, Salmon AH, Squire JM, Bates DO, Neal CR: Resolution of the three dimensional structure of components of the glomerular filtration barrier. BMC Nephrol 2014;15:24.

35 Neal CR, Muston PR, Njegovan D, Verrill R, Harper SJ, Deen WM, Bates DO: Glomerular filtration into the subpodocyte space is highly restricted under physiological perfusion conditions. Am J Physiol Renal Physiol 2007;293:F1787-1798.

36 Salmon AH, Toma I, Sipos A, Muston PR, Harper SJ, Bates DO, Neal CR, Peti-Peterdi J: Evidence for restriction of fluid and solute movement across the glomerular capillary wall by the subpodocyte space. Am J Physiol Renal Physiol 2007;293:F1777-1786.

37 Palatini P: Glomerular hyperfiltration: A marker of early renal damage in pre-diabetes and prehypertension. Nephrol Dial Transplant 2012;27:1708-1714.

38 Frische S: Glomerular filtration rate in early diabetes: Ongoing discussions of causes and mechanisms. J Nephrol 2011;24:537-540.

39 Mogensen CE: Twelve shifting paradigms in diabetic renal disease and hypertension. Diabetes Res Clin Pract 2008;82:S2-S9.

40 Wuerzner G, Pruijm M, Maillard M, Bovet P, Renaud C, Burnier M, Bochud M: Marked association between obesity and glomerular hyperfiltration: A cross-sectional study in an african population. Am J Kidney Dis 2010;56:303-312.

41 Kramer H, Luke A, Bidani A, Cao G, Cooper R, McGee D: Obesity and prevalent and incident ckd: The hypertension detection and follow-up program. Am J Kidney Dis 2005;46:587-594.

42 Helal I, Fick-Brosnahan GM, Reed-Gitomer B, Schrier RW: Glomerular hyperfiltration: Definitions, mechanisms and clinical implications. Nat Rev Nephrol 2012;8:293-300.

43 Gates GF: Filtration fraction and its implications for radionuclide renography using diethylenetriaminepentaacetic acid and mercaptoacetyltriglycine. Clin Nucl Med 2004;29:231-237.

44 Thomson SC, Blantz RC: Biophysics of glomerular filtration. Compr Physiol 2012;2:1671-1699.

45 Conrad KP, Jeyabalan A, Danielson LA, Kerchner LJ, Novak J: Role of relaxin in maternal renal vasodilation of pregnancy. Ann N Y Acad Sci 2005;1041:147-154.

46 Hostetter TH, Olson JL, Rennke HG, Venkatachalam MA, Brenner BM: Hyperfiltration in remnant nephrons: A potentially adverse response to renal ablation. Am J Physiol 1981;241:F85-93.

47 Zatz R, Meyer TW, Rennke HG, Brenner BM: Predominance of hemodynamic rather than metabolic factors in the pathogenesis of diabetic glomerulopathy. Proc Natl Acad Sci USA 1985;82:5963-5967.

48 Srivastava T, McCarthy ET, Sharma R, Cudmore PA, Sharma M, Johnson ML, Bonewald LF: Prostaglandin $\mathrm{e}(2)$ is crucial in the response of podocytes to fluid flow shear stress. J Cell Commun Signal 2010;4:79-90.

49 Huang C, Bruggeman LA, Hydo LM, Miller RT: Shear stress induces cell apoptosis via a c-src-phospholipase d-mtor signaling pathway in cultured podocytes. Exp Cell Res 2012;318:1075-1085.

50 Grahammer F, Wanner N, Huber TB: Mtor controls kidney epithelia in health and disease. Nephrol Dial Transplant 2014;29:i9-i18.

51 Srivastava T, McCarthy ET, Sharma R, Kats A, Carlton CG, Alon US, Cudmore PA, El-Meanawy A, Sharma M: Fluid flow shear stress upregulates prostanoid receptor EP2 but not EP4 in murine podocytes. Prostaglandins Other Lipid Mediat 2013;104-105:49-57.

52 Srivastava T, Alon US, Cudmore PA, Tarakji B, Kats A, Garola RE, Duncan RS, McCarthy ET, Sharma R, Johnson ML, Bonewald LF, El-Meanawy A, Savin VJ, Sharma M: Cyclooxygenase-2, prostaglandin E2 and prostanoid receptor EP2 in fluid flow shear stress mediated injury in solitary kidney. Am J Physiol Renal Physiol 2014;307:F1323-F1333. 


\section{Kidney \\ Blood Pressure Research}

Pichler Sekulic/Sekulic: Rheological Influence Upon the Podocyte

53 Ganesh T: Prostanoid receptor EP2 as a therapeutic target. J Med Chem 2014;57:4454-4465.

54 Hoffman BD, Grashoff C, Schwartz MA: Dynamic molecular processes mediate cellular mechanotransduction. Nature 2011;475:316-323.

55 Cohen CD, Klingenhoff A, Boucherot A, Nitsche A, Henger A, Brunner B, Schmid H, Merkle M, Saleem MA, Koller KP, Werner T, Gröne HJ, Nelson PJ, Kretzler M: Comparative promoter analysis allows de novo identification of specialized cell junction-associated proteins. Proc Natl Acad Sci USA 2006;103:5682-5687.

56 Tzima E, Irani-Tehrani M, Kiosses WB, Dejana E, Schultz DA, Engelhardt B, Cao G, DeLisser H, Schwartz MA: A mechanosensory complex that mediates the endothelial cell response to fluid shear stress. Nature 2005;437:426-431.

57 Chrétien ML, Zhang M, Jackson MR, Kapus A, Langille BL: Mechanotransduction by endothelial cells is locally generated, direction-dependent, and ligand-specific. J Cell Physiol 2010;224:352-361.

58 Friedland JC, Lee MH, Boettiger D: Mechanically activated integrin switch controls alpha5beta1 function. Science 2009;323:642-644.

59 Patrakka J, Tryggvason K: Molecular make-up of the glomerular filtration barrier. Biochem Biophys Res Commun 2010;396:164-169.

60 Reiser J, Polu KR, Möller CC, Kenlan P, Altintas MM, Wei C, Faul C, Herbert S, Villegas I, Avila-Casado C, McGee M, Sugimoto H, Brown D, Kalluri R, Mundel P, Smith PL, Clapham DE, Pollak MR: Trpc6 is a glomerular slit diaphragm-associated channel required for normal renal function. Nat Genet 2005;37:739744.

61 Greka A, Mundel P: Calcium regulates podocyte actin dynamics. Semin Nephrol 2012;32:319-326.

62 Tian D, Jacobo SM, Billing D, Rozkalne A, Gage SD, Anagnostou T, Pavenstädt H, Pavenstaedt H, Hsu HH, Schlondorff J, Ramos A, Greka A: Antagonistic regulation of actin dynamics and cell motility by trpc5 and trpc6 channels. Sci Signal 2010;3:ra77.

63 Babelova A, Jansen F, Sander K, Löhn M, Schäfer L, Fork C, Ruetten H, Plettenburg O, Stark H, Daniel C, Amann K, Pavenstädt H, Jung O, Brandes RP: Activation of rac-1 and rhoa contributes to podocyte injury in chronic kidney disease. PLoS One 2013;8:e80328.

64 Wilson C, Dryer SE: A mutation in trpc6 channels abolishes their activation by hypoosmotic stretch but does not affect activation by diacylglycerol or g protein signaling cascades. Am J Physiol Renal Physiol 2014;306:F1018-1025.

65 Morton MJ, Hutchinson K, Mathieson PW, Witherden IR, Saleem MA, Hunter M: Human podocytes possess a stretch-sensitive, ca2+-activated k+ channel: Potential implications for the control of glomerular filtration. J Am Soc Nephrol 2004;15:2981-2987.

66 Durvasula RV, Shankland SJ: Mechanical strain increases sparc levels in podocytes: Implications for glomerulosclerosis. Am J Physiol Renal Physiol 2005;289:F577-584.

67 Schordan S, Schordan E, Endlich K, Endlich N: Alphav-integrins mediate the mechanoprotective action of osteopontin in podocytes. Am J Physiol Renal Physiol 2011;300:F119-132.

68 Faour WH, Gomi K, Kennedy CR: Pge(2) induces cox-2 expression in podocytes via the ep(4) receptor through a pka-independent mechanism. Cell Signal 2008;20:2156-2164.

69 Stitt-Cavanagh EM, Faour WH, Takami K, Carter A, Vanderhyden B, Guan Y, Schneider A, Breyer MD, Kennedy CR: A maladaptive role for ep4 receptors in podocytes. J Am Soc Nephrol 2010;21:1678-1690.

70 Anderson S, Meyer TW, Rennke HG, Brenner BM: Control of glomerular hypertension limits glomerular injury in rats with reduced renal mass. J Clin Invest 1985;76:612-619.

71 Campbell KN, Raij L, Mundel P: Role of angiotensin ii in the development of nephropathy and podocytopathy of diabetes. Curr Diabetes Rev 2011;7:3-7.

72 Hakroush S, Cebulla A, Schaldecker T, Behr D, Mundel P, Weins A: Extensive podocyte loss triggers a rapid parietal epithelial cell response. J Am Soc Nephrol 2014;25:927-938. 